\title{
Sciendo
}

Ethics \& Bioethics (in Central Europe), 2020, 10 (1-2), 40-47

DOI:10.2478/ebce-2020-0006

\section{The Liverpool Care Pathway for the dying patient: Euthanasia through the back door, or the sign of poor death education? ${ }^{1}$}

\begin{abstract}
Allan R. Jones ${ }^{2}$
Abstract

The Liverpool Care Pathway for the Dying Patient (LCP) was an integrated care pathway for patients in the final days or hours of life, developed at the Royal Liverpool University Hospital in conjunction with the Marie Curie Palliative Care Institute, Liverpool. The LCP became increasingly the normative style of care for patients in the terminal stage across NHS England from the 1990s onwards. Following significant questions raised in Parliament, by the media and other stakeholders, an independent review panel was established under Baroness Neuberger in 2013 to investigate the LCP. The findings of the panel were published as More Care Less Pathway: a Review of the Liverpool Care Pathway identifying significant failings in the delivery of the LCP thus leading to it being phased out some six months later. Rather than being euthanasia through the backdoor, many of the criticisms of the LCP and its poor implementation are indicative of poor communication, limited knowledge of the dying process and a paucity of death education.
\end{abstract}

Keywords: The Liverpool Care Pathway, communication, culture shift \& death education

\section{Introduction}

During the 1990s there was a concerted effort to develop Integrated Care Pathways across the National Health Service in the United Kingdom, this American market-based model of healthcare was created in the 1980s to be of benefit to patients by focusing upon the work of multi-disciplinary teams providing the best standard of care and to be more cost effective for insurance companies. The Liverpool Care Pathway for Adults in the Last Days and Hours of Life (the LCP) was developed using this model, through applying the principles of hospice style care to this pathway approach; it became the normative style of care for terminally ill patients for over a decade in parts of the United Kingdom. Following significant questions raised in Parliament, a campaign by the media and other stakeholders, with the particular charge that the LCP was euthanasia through the back door, the British Government established an independent review panel in 2013 to investigate the claims being made against the LCP. The panel's findings: More Care, Less Pathway: A Review of the Liverpool Care Pathway identified significant failings in the delivery of the LCP (Neuberger et al., 2013), but that the LCP itself was a good tool for the provision of care, the panel recommended that the LCP be phased out over the following six to twelve months. The key finding of the Review was that the LCP had been implemented poorly, primarily due to a lack of poor communication with relatives who often had a limited knowledge of the dying process. Consideration of the failures of the LCP cannot be confined to the academic and medical world alone, rather the perceived failings of the LCP are indicative of the problems in discussing death and dying in wider society and that death education might alleviate such problems in the future.

\footnotetext{
${ }^{1}$ The paper was presented at the international conference End of Life and Euthanasia - Intersection of Issues and Questions held in Prague (Czech Republic) on 4-5 November 2019.

${ }^{2}$ Cardiff University, The School of History Archaeology and Religious Studies, St Padarn Institute, Cardiff (Wales) \& KU Leuven, The Faculty of Theology and Religious Studies, Leuven (Belgium); JonesAR23@cardiff.ac.uk
} 


\section{The Liverpool Care Pathway}

The LCP was developed at the Royal Liverpool University Hospital in conjunction with the Marie Curie Palliative Care Institute in the early 1990s (Kinder \& Ellershaw, 2003, p. 11). Much of the earliest work in developing the LCP was to help patients with cancer, but the scope was widened for all patients in the terminal phase. The key aim of the LCP was to provide the best hospice style care for the terminally ill, be they in a hospice, an acute hospital, a care home or living in the community. Integral to the LCP was the training of healthcare staff across an organisation to provide qualitative Palliative Care, without having to involve the limited resources of Palliative Care specialists on a case by case basis (Kinder \& Ellershaw, 2003, p. 11). Only those who had been diagnosed as dying could be placed on the LCP (Kinder \& Ellershaw, 2003, p. 11), namely that they were in the active dying phase with "the body shutting down and the person ... letting go" (Neuberger et al., 2013, p. 14). The approach was goalorientated, and the specific goals were to be achieved over three phases. The first two phases of the LCP focus upon the physical, spiritual, psychological and emotional care of the patient, and include communicating with the patient, family and General Practitioner. The first phase of the LCP involved thoroughly assessing the patient's condition, including common symptoms in the dying phase, such as: inability to swallow, nausea, vomiting, constipation, confusion, agitation, restlessness, distress, urinary tract problems, need of a catheter, respiratory tract problems or pain (Kinder \& Ellershaw, 2003, p. 19). Having made such an assessment, the healthcare team decide whether non-essential medication and inappropriate interventions such as blood tests, antibiotics, I.V. fluids, should be discontinued and whether to increase or introduce medication for pain relief or to ease symptoms, such as those stated above (Kinder \& Ellershaw, 2003, p. 19). The initial assessment included addressing issues such as cardio-pulmonary resuscitation, religious and spiritual support, communicating with the family and others with matters such as who is to be informed when the patient dies, and that the LCP and its use be explained and discussed with the family (Kinder \& Ellershaw, 2003 p. 20).

Once these initial goals had been achieved, the second phase begins, with assessing the patient's condition on regular four hourly intervals including levels of pain and symptom management (Kinder \& Ellershaw, 2003, p. 19) and addressing any needs such as increasing the use of opioids. The second phase also involved meeting the psychological and emotional needs of the patient and his or her carers (Kinder \& Ellershaw, 2003, p. 19). This second phase continues until the patient dies, no matter how long that may be, unless the patient is deemed fit to be taken off the LCP. The third phase of the LCP occurs after the patient has died and includes following local hospital protocols, as well as focusing upon the needs of grieving relatives (Kinder \& Ellershaw, 2003, pp. 26-27).

The LCP was endorsed by the UK Government and implemented across National Health Service England (Department of Health, End of Life Care Strategy, 2008, pp. 66-67), and subsequently National Health Service Scotland and Health and Social Care Northern Ireland; the Welsh Government together with the National Health Service Wales developed the All Wales End of Life Care Pathway for the Dying Patient, based on the LCP (Welsh Assembly Government, 2006, 30). The LCP became normative for patients in the terminal stage across the United Kingdom; in 2013: " 130,000 of the 450,000 patients who die in hospital care every year die while being cared for on the pathway" (Hansard, 2013, Vol. 556). The LCP was also in use in more than 20 different countries, with pilot schemes taking place in Argentina, Italy, India, The Netherlands; some of which incorporated the LCP into their healthcare settings (McCartney, 2012, p. 345; Cauldwell \& Stone, 2015, pp. 94-98; Zinner, 2013a, pp. 30-31; Zinner, 2013b, pp. 27-28; Veerbeek, 2008; Smeding, Bolger \& Ellershaw, 2011, pp. 190-205). A significant voice that heralded the introduction of this approach to care was that of Dame 
Cicely Saunders, founder of St Christopher's Hospice in London, and pioneer of modern hospice care (Ellershaw \& Wilkinson, pp. v-vi). With such positive endorsements for the focus on patient-centred care, based upon the well proven practice of hospice care in which the sick person with all his/her needs being met, what could possibly have gone so wrong as to lead to Parliamentarians, the press, and grieving family and friends to question as to whether the LCP was euthanasia through the back door, particularly its use in the acute hospital setting, where most people die (Public Health England, 2018).

\section{Euthanasia through the back door the media campaign}

The first to raise concerns over the LCP was a medical doctor, Gillian Craig, who in 2008 looked particularly at the issue of hydration and sedation on the LCP (Craig, 2008, pp. 155160). Others followed suit in questioning the precision of diagnosing death (Millard et al., 2009), Dr Hargreaves noted that: "some patients were being 'wrongly' put on the pathway, which created a 'self-fulfilling prophecy' that they would die" (Devlin, 2009). Diagnosing death, removing clinically assisted nutrition and hydration, and heavily sedating patients, led to what some have described as terminal sedation: "the deliberate lowering of a patient's level of consciousness in the last stages of life ... the practice usually involves continuous intravenous infusions of sedatives, but no hydration or nutrition" (Wyatt, 2015, p. 169). Yet neither heavy sedation nor withdrawing clinically assisted nutrition and hydration were goals to be achieved or even discussed in LCP documents (Kinder \& Ellershaw, 2003, pp. 18-25). From this there followed a series of stories in the media from distressed relatives who had witnessed the death of close relatives on the LCP: "Sentenced to death on the NHS" (Devlin, 2009), "My diary of mum's awful death on the Liverpool Care Pathway: Nurse's heart-rending account of how doctors decided to put her mother on 'pathway to death"' (Rawstorne, 2012), "It was murder, says son of woman 'starved to death' on Liverpool Care Pathway as he calls for police inquiry" (Smith, 2013). Social media became a forum in which the LCP came to be described as "the death pathway". Concerns were raised in Westminster (Davies, 2013), leading to the Minister of State for Care Services appointing an independent panel to review the use and experience of the LCP (Neuberger et al., 2013, p. 13).

This independent panel met between February and June 2013 and examined 483 submissions from members of the public, most of whom had experience of the LCP as relatives or carers, 91 from health and care professionals, and 36 professional bodies and other organisations, as well as visiting hospitals and meeting with a variety of stakeholders (Neuberger et al., 2013, p. 57). The results of this panel were published as More Care Less Pathway, a Review of the Liverpool Care Pathway and identified significant failings in the delivery of the LCP leading, as a result of its recommendations, to the LCP being phased out six months later (Neuberger et al., 2013, p. 57). The Panel was clear that the LCP was a wellintentioned approach at providing the best of care for those in the terminal phase. The main criticisms and subsequent suggestions for the future of end of life care in the terminal stage related to poor implementation and poor communication, and included 44 recommendations (Neuberger et al., 2013, pp. 52-59). As well as receiving negative feedback, the Panel also received positive input from families whose relatives had been placed on the LCP that found no place in the press (Neuberger et al., 2013, pp. 14, 23). In light of the publication of the Review, members of the medical profession expressed their own support for the LCP, including those who stated that they would wish, in the case of their own terminal illness, to be placed on the LCP (Chinthapalli, 2013a; Chinthapalli, 2013b; Chinthapalli, 2013c).

The LCP had become such a toxic issue, that, whilst the recommendations could have been implemented, this was not deemed to be feasible owing to the public outcry and the attention in the press (Neuberger et al., p. 17), "the pathway had become a brand, 'and now the brand is damaged beyond fixing"" (Hawkes, 2013). The Panel, whilst taking into consideration the 
claims by some relatives that their lost loved ones had been euthanised, did not examine the issue of euthanasia, rather they addressed the specific issues regarding the use of opioids and clinically assisted nutrition and hydration in the terminal stage, misunderstandings and misconceptions and the lack of good communication on the part of health care workers (Neuberger et al., 2013, p. 29-30). It is worth noting that no cases regarding the use of the LCP ever came to court.

In 2014 the LCP was phased out in accordance with the recommendation of the Review, yet "the decision to phase out the LCP was made on the basis of little more than an accumulation of anecdotal evidence" and not based on clinical research" (Sleeman, 2013). There is a still a common belief, found in social media, ${ }^{3}$ that this was but a whitewashing and rebranding exercise and that the LCP is still in use, but under a new name. In Wales The All Wales Care Pathway for the Last Days of Life, based upon the LCP, was reviewed and the recommendation of More Care, Less Pathway, as well as those of the National Institute for Health and Care Excellence Guidelines were put in place (Seymour \& Clark, 2018, p. 12; NICE, 2015). Despite the rapid phasing out of the LCP in NHS England, NHS Scotland, and the HSC in Northern Ireland, there are those such as Professor Pullicino, one of the most ardent critics of the LCP, who stated that the LCP had changed the culture of care for the terminally ill, and that despite having being phased out, that same culture and the same problems persist (Pullicino, 2015). The charge that the NHS is engaged in covert involuntary euthanasia is still present in social media, despite there being no evidence to back up such claims. The LCP has had a profound effect upon end of life care in NHS England, "many health professionals are frustrated at the loss of the LCP, and some fear that that care of the dying may be set back years" (Regnard, 2014). This concern cannot ignore the wider cultural difficulties that exist concerning the questions surrounding death and dying among the general populace and the limited knowledge of this process that ordinary people have, that may in turn have led to the strong reactions against the LCP and the new personalised end of life care plans that were developed to replace the LCP.

\section{Limited knowledge of the dying process and the development of death education initiatives}

Death and the dying are subjects that are not frequently discussed, they have become taboo subjects; invariably, the few times in life in which death is encountered is when a loved one dies (IPSOS-Mori, 2010, pp. 3, 20-21) and for many, as a result of increasing life spans, death has become a rare event which is first encountered in adulthood. This is a fairly recent phenomenon, in the past: "funerals were a community affair. Washing the body, laying it out, would all have been done by family members and friends" (Battersby, 2012). Death was once something that affected everybody in a local community and there was an awareness the procedures for caring for a dying person and what would have happened when the end finally came. Part of the reason for death having become such an unfamiliar process over the last century is that it was outsourced to the medical profession and funeral directors (Span, 2013). In the medical setting the language around death and dying uses specialised vocabulary, which is alien and unfamiliar to those not engaged or employed within the field of healthcare. When confronted with news of terminal illness and death, many people are bewildered by what can feel like an information overload, especially when trying to come to terms with the news of a terminal illness (IPSOS-Mori, 2010, p. 3). Being told that a relative was going to be placed on

\footnotetext{
${ }^{3}$ There are a number of Facebook Groups and Twitter accounts that perpetuate these theories and ideas, with names such as: The Liverpool Care Pathway Protest Group, LCP Awareness UK, Liverpool Care or Death Pathway, Help Put a Stop to Liverpool Care Pathway, Liverpool Care Pathway Say No, Petition against the Liverpool Care Pathway, Stop using the Liverpool Care Pathway without Consent now and there are also Blogs such as: http://liverpool-care-pathway-a-national-sc.blogspot.com
} 
the LCP raised the question as to what a Pathway is and what this has to do with Liverpool. As well as the misconceptions that abound concerning Do Not Resuscitate Orders, the use of pain relief, and the withdrawal of ordinary medical treatment. Often the intricate and vital information that those living with a terminal illness receive, as well as their family and friends, is only given once the diagnosis is made. Kübler-Ross, Kessler, Nolan, Rumbold, Weismann identify in their various approaches that patients will often be in a state of denial at this stage, (Kübler-Ross \& Kessler, 2005, p. 7; Nolan, 2012, p. 24), these patients and their families are often not in a position to appreciate the information that is given to them. In the case of the LCP this situation was not helped by the lack of communication from healthcare workers when it came to placing patients on the LCP (Neuberger et al., 2013, p. 49). In its conclusions the Review identified that the problems surrounding the LCP were indicative of the current cultural climate in which death is no longer part of life, but rather has become a taboo which receives scant attention. The Review states clearly that: "While the Government cannot itself change the way the nation thinks about death and dying, the professional bodies can play their part by taking a lead among their members" (Neuberger et al., 2013, p. 49). As such the onus is placed upon medical staff who are invited to be "prepared to talk openly and honestly about dying, death and bereavement, accepting these as a normal part of life" (Neuberger et al., 2013, p. 49). Whilst medical staff, and professional bodies can play a part, the conversations have to begin before people are diagnosed as having a terminal illness.

In the context of the LCP, whilst informal death education initiatives may not have prevented the public outcry, they may have lessened its ferocity. More Care, Less Pathway in its concluding comments noted: "The Review panel strongly supports the work of organisations that promote public awareness of dying, death and bereavement," (Neuberger et al., 2012, p. 49). There are contemporary initiatives such as Death Cafés, the Death over Dinner movement, and others that could meet this need (Hebb, 2018). There is a marked increase in the number of books dealing with the subjects of death, dying and palliative care, authors such as Kathryn Mannix and Atul Gawande, who bring their varied experiences and knowledge of palliative care, encounters with patients and their own personal stories who through their writings bring that knowledge to the wider public (Mannix, 2017; Gawande, 2015). The objective of these initiatives is: "to increase awareness of death with a view to helping people make the most of their (finite) lives" (What is Death Café?' https://deathcafe.com/what/). The question is whether death education can reach all sections of society? Barnard notes that these initiatives are "extremely young", and that there is a lack of scientific research demonstrating their utility; they are however at least steps in the right direction for creating the necessary 'cultural shift' (Barnard, 2016, pp. 237-238). If these initiatives enable conversations to begin, and barriers to be broken down so that everybody has an awareness and understanding of terminal illnesses, end of life care, palliative care and death itself, patients, together with their relatives and friends, will be able to fulfil the vision that Cicely Saunders worked for with healthcare staff supporting patients and relatives at the end of life: "You matter because you are you, and you matter to the end of your life. We will do all we can not only to help you die peacefully, but also to live until you die" (Tributes to Dame Cicely Saunders).

\section{Conclusion}

Cicely Saunders' vision for care at the end of life underpins the principles, methodology and practice of what has become hospice care and in turn palliative care and a significant part of the vision of the authors of the LCP. With the increase in longevity and of those living with cancer, life-limiting conditions and comorbidities, the need for good qualitative end of life care will only increase. Taking Saunders' principles on board, the LCP proved to be, at least in theory, an excellent way to achieve the best care for those in the terminal phase. Among the LCP's flaws was the overly optimistic move from palliative care as a specialism to it becoming 
a generic form of care that anybody could learn to deliver. Indicative of this flaw was the lack of good communication, including communicating with the terminally ill and their relatives. From what has been learnt from the LCP there needs to be a more open, more transparent and more honest approach to the issue of what happens when we are dying, and what happens when we die, and that this should not be left until the last days of life. The experience of the LCP, and the campaign against it, highlight the worst-case scenario of poor communication, one which was never counterbalanced with information on what the LCP was, nor its benefits. The greatest lesson of the LCP seems to be that there is a need for better communication on the part of healthcare staff and healthcare agencies and organisations such as the NHS, but also the need for wider conversations and a shift in culture surrounding the issue of death and dying.

This cultural change is necessary for those working in healthcare, those who are sick, and importantly for those engaged in caring for their sick relatives and friends; of equal importance is the wider societal shift in which a greater awareness of the dying process and death itself are better understood by everybody. When all is said and done, this is an issue that will eventually affect each of us. As has been seen there are various death education initiatives that have developed recently, as well as a new genre of literature, both in print and online, dealing with the many questions that people may pose and upon which they may wish to reflect. One of the significant challenges is to heighten the awareness of these initiatives and to include them as an intrinsic part of community-based health education, as well as for these issues to be discussed in the compulsory sector, namely in primary and secondary education. Changing the culture from one in which death is treated as a taboo to being a subject that is discussed freely is an enormous task, and yet there are opportunities in which the subject of death, dying and end of life care can be gently introduced to the general public as has been demonstrated in the new initiatives that are becoming a burgeoning industry.

\section{References}

BARNARD, D. (2016): On our difficulties speaking to and about the dying. In: S. J. Younger \& R. M. Arnold (eds.): The Oxford handbook of ethics at the end of life. Oxford: Oxford University Press, pp. 227-241.

BATTERSBY, M. (2012): The Death Café Movement: tea and Mortality. In: The Independent, [online] [Retrieved September 19, 2019] https://www.independent.co.uk/life-style/health-andfamilies/features/the-death-cafe-movement-tea-and-mortality-8082399.html

CAULDWELL, K. \& STONE, P. (2015): The changing nature of end of life Care. In: Indian Journal of Medical and Paediatric Oncology: Official Journal of Indian Society of Medical \& Paediatric Oncology, 36(2), pp. 94-98. [online] [Retrieved May 5, 2019] Available at: https://www.ncbi.nlm.nih.gov/pmc/articles/PMC4477384/

CHINTHAPALLI, K. (2013a): The birth and death of the Liverpool Care Pathway. In: BMJ, 347:f4669. [online] [Retrieved October 1, 2019] Available at: https://doi.org/10.1136/ bmj.f4669

CHINTHAPALLI, K. (2013b): Nine out of 10 palliative care experts would choose Liverpool care pathway for themselves. In: $B M J, 346: f 1303$. [online] [Retrieved October 1, 2019] Available at: https://doi.org/10.1136/bmj.f1303

CHINTHAPALLI, K. (2013c): The Liverpool care pathway: What do specialists think? In: $B M J$, 346:f1184 [online] [Retrieved October 01, 2019] Available at: https://doi.org/10.1136/bmj.f1 184

CRAIG, G. (2008): Palliative care in overdrive: Patients in danger. In: American Journal of Hospice and Palliative Medicine ${ }^{\circledR}$, 25(2), pp. 155-160. [online] [Retrieved September 29, 2019] Available at: https://doi.org/10.1177/1049909107312596

DAVIES, M. P. G. (2013): quoted in: The House of Commons Debate on the Liverpool Care Pathway 08 January 2013. In: Hansard, Volume 556 [online] [Retrieved September 30, 2019] 
Available at: https://hansard.parliament.uk/Commons/2013-01-08/debates/13010824000001/ LiverpoolCarePathway

DEPARTMENT OF HEALTH (2008): End of life care strategy, [online] [Retrieved September 27, 2019] Available at: https://assets.publishing.service.gov.uk/government/ uploads/system/uploads/attachment_data/file/136431/End_of_life_strategy.pdf

DEVLIN, K. (2009): Sentenced to death on the NHS. In: The Telegraph [online] [Retrieved September 25, 2019] Available at: https://www.telegraph.co.uk/news/health/news/6127514/ Sentenced-to-death-on-the-NHS.html

ELLERSHAW, J. \& WILKINSON, S. (2003): Care of the dying: A pathway to excellence. Oxford: Oxford University Press.

ELLERSHAW, J. \& WILKINSON, S. (2011): Care of the dying: A pathway to excellence, $2^{\text {nd }}$ ed. Oxford: Oxford University Press.

GAWANDE, A. (2015): Being mortal. London: Profile Books.

HAWKES, N. (2013): Liverpool care pathway is scrapped after review finds it was not well used. In: $B M J, 347: \mathrm{f4568}$ [online] [Retrieved October 01, 2019] Available at: https://doi.org/10.1136/bmj.f4568

HEBB, M. (2018): Let's talk about death (over dinner). New York, USA: Da Capo Publishing. IPSOS-MORI (2010): Attitudes towards death and dying in the East of England - Qualitative Report [online] [Retrieved October 01, 2019] Available at: https://www.ipsos.com /sites/default/files/migrations/en-uk/files/Assets/Docs/Publications/attitudes-towards-dying2011-qualitative-report.pdf

KINDER, C. \& ELLERSHAW, J. (2003): How to use the Liverpool Care Pathway for the dying patient. In: J. Ellershaw \& S. Wilkinson (eds.): Care of the dying: A pathway to excellence. Oxford: Oxford University Press, pp. 11-41.

KÜBLER-ROSS, E. \& KESSLER, D. (2005): On Grief and Grieving. London: Simon \& Schuster.

LEADERSHIP ALLIANCE FOR THE CARE OF DYING PEOPLE (2013): One chance to get it right. [online] [Retrieved September 29, 2019] Available at: https://wales.pallcare.info/ files/One_chance_to_get_it_right.pdf

MCCARTNEY, $\overline{\text { M. }} . \overline{(2012)}$ ): The assault on the Liverpool Care Pathway. In: BMJ, 345:e7316. [online] [Retrieved October 1, 2019] Available at: https://doi.org/10.1136/bmj.e7316

MANNIX, K. (2017): With the end in mind. London: Collins.

MILlard, P. H., COLE, A., HARGREAVES, P., HILL, D., NEGUS, E. \& DOWAGER LADY SALISBURY (2009): Dying patients. In: The Telegraph. [online] [Retrieved September 29, 2019] Available at: https://www.telegraph.co.uk/comment/letters/ 6133157/Dying-patients.html

NATIONAL INSTITUTE FOR HEALTH AND CARE EXCELLENCE (NICE) (2015) Care of dying adults in the last days of life. [online] [Retrieved September 22, 2019] Available at: https://www.wales.pallcare.info/files/NICE\%20Care\%20of\%20dying\%20adults\%20in\%20th e\%20last $\% 20$ days $\% 20$ of $\% 201$ life $\% 20 \mathrm{NG31.pdf}$

NEUBERGER, J., GUTHRIE, C., AARONOVITCH, D., HAMEED, K., BONSER, T., HARRIES, R., CHARLESWORTH-SMITH, D., JACKSON, E., COX, D. \& WALLE, S. (2013): More Care Less Pathway, a Review of the Liverpool Care Pathway. [online] [Retrieved September 29, 2019] Available at: https://assets.publishing.service.gov.uk/government /uploads/system/uploads/attachment_data/file/212450/Liverpool_Care_Pathway.pdf

NOLAN, S. (2012): Spiritual care at the end of life: The Chaplain as a 'Hopeful Presence.' London: Jessica Kingsley Publishers.

PUBLIC HEALTH ENGLAND (2018): Statistical commentary: End of life care profiles. [online] [Retrieved September 30, 2019] Available at: https://www.gov.uk/government/ 
publications/end-of-life-care-profiles-february-2018-update/statistical-commentary-end-oflife-care-profiles-february-2018-update

PULLICINO, P. (2015): The new end-of-life guidelines are lethal. In: The Telegraph. [online] [Retrieved September 27, 2019] Available at: https://www.telegraph.co.uk/news/nhs/117 79394/The-new-end-of-life-guidelines-are-lethal.html

RAWSTORNE, T. (2012): My diary of mum's awful death on the Liverpool Care Pathway: Nurse's heart-rending account of how doctors decided to put her mother on 'pathway to death. In: The Mail on Sunday. [online] [Retrieved September 25, 2019] Available at: https://www.dailymail.co.uk/news/article-2220409/My-diary-mums-awful-death-LiverpoolCare-Pathway-Nurses-heart-rending-account-doctors-decided-mother-pathway-death.html REGNARD, C. (2014): Blaming care pathway 'like blaming Highway Code.' [online] [Retrieved October 3, 2019] Available at: https://www.bbc.co.uk/news/health-25757322

SEYMOUR, J. \& CLARK, D. (2018): The Liverpool Care Pathway for the Dying Patient: a critical analysis of its rise, demise and legacy in England [version 1; peer review: 2 approved]. Wellcome Open Res, 3(15) [online] [Retrieved September 22, 2019] Available at: https://doaj.org/article/4ca295abe8ed47f99678492500f3dcde

SLEEMAN, K. (2013): The Liverpool care pathway: A cautionary tale. In: BMJ, 347:f4779 [online] [Retrieved October 1, 2019] Available at: https://doi.org/10.1136/bmj.f4779

SMEDING, R., BOLGER, M. \& ELLERSHAW, J. (2011): International development of the Liverpool Care of the Dying Patient. In: J. Ellershaw \& S. Wilkinson (eds.): Care of the Dying: A Pathway to Excellence, $2^{\text {nd }}$ ed. Oxford: Oxford University Press, pp. 190-205.

SMITH, J. (2013): It was murder, says son of woman 'starved to death' on Liverpool Care Pathway as he calls for police inquiry. In: The Daily Mail. [online] [Retrieved September 25, 2019] Available at: https://www.dailymail.co.uk/news/article-2513136/It-murder-says-sonwoman-starved-death-Liverpool-Care-Pathway-calls-police-inquiry.html

SPAN, P. (2013): Death Be Not Decaffeinated: Over Cup, Groups Face Taboo. In: The New York Times. [online] [Retrieved September 09, 2019] Available at: https://newoldage.blogs. nytimes.com/2013/06/16/death-be-not-decaffeinated-over-cup-groups-face-taboo/?.php=true \& type $=$ blogs\&_r $=0$

TRIBUTES TO DAME CICELY SAUNDERS [online] [Retrieved September 25, 2019] Available at: https://www.stchristophers.org.uk/about/damecicelysaunders/tributes

WELSH ASSEMBLY GOVERNMENT (2006): Welsh Health Circular (WHC 2006 30). [online] [Retrieved September 29, 2019] Available at: http://www.wales.nhs.uk/documents /WHC_2006_030-English.pdf

WHAT IS DEATH CAFÉ? [online] [Retrieved September 19, 2019] Available at: https://de athcafe.com/what/

VEERBEEK, L. (2008): Care and quality of life in the dying phase: The contribution of the Liverpool Care Pathway for the dying patient. Rotterdam: Erasmus University. [online] [Retrieved January 16, 2019] Available at: http://hdl.handle.net/1765/13429

WYATT, J. (2015): Right to die. Nottingham: Inter-Varsity Press.

ZINNER, M. (2013a): Der "Liverpool Care Pathway". Norderstedt: Grin Verlag.

ZINNER, M. (2013b): Sterbenbegleitung im kontext des Liverpool Care Pathway. Hamburg: Diplomica Verlag. 